\title{
Social Work with the Elderly: A Rural Study
}

\author{
Kaushalendra Pratap Singh \\ School of Social Work at IGNOU, New Delhi, India
}

\begin{abstract}
Social work profession enhances the well-being of people by intervening at the points where people find difficulties. Interventions are intended to assist clients in alleviating problems impeding their well-being. Old age is the last phase of one's life where the elderly confront many challenges with regard to their physical and mental health and support systems. The quality of life of rural elderly in India is deteriorating because of inadequate facilities and weak support systems. This paper is based on the impact of social work intervention in improving the mental health condition of a group of elderly people residing in rural India. The study was conducted in the Madwana village of Lucknow district in Uttar Pradesh. The entire process of the study was facilitated by a Lucknow based NGO - 'Aarambh Welfare Foundation'. The design of the study was quasi experimental. Various activities were conducted as a part of social work intervention: counselling, motivational, awareness, and sensitization programmes. During intervention various social work methods, principles and values were applied, for a period of six months. A structured interview schedule was used for data collection. The study revealed that social work intervention has reduced the feeling of depression, loneliness, and anxiety, resulting in improved quality of life among rural elderly.
\end{abstract}

Keywords Social Work Intervention, Mental Health, and Rural Elderly

\section{Introduction}

Today, the number of people reaching old age is much greater. This is because life expectancy has increased dramatically. It also implies the need for elder care. In India, the family has been the traditional social institution for the support and care of the elderly (Rajan and Kumar, 2003). Structural changes in the Indian family system have affected the well-being of the elderly. Social work profession enhances the well-being of people by intervening at the point where people find difficulties through various intervention strategies. In this connection, the present paper aims to determine the application of social work in helping the rural elderly, who remain in a stressful situation. The specific objectives of the study are:

- To assess the mental health condition of the aged in the existing social environment,

- To apply social work intervention among the aged by addressing the issues emerging from their mental health condition; and

- To determine the impact of social work intervention.

\section{Research Methodology}

The present study was conducted in the Madwana village of Lucknow district in Uttar Pradesh. The design of the study was quasi experimental that includes a baseline study, intervention and evaluation. In this study, it was not possible to achieve random assignments of subjects to experimental, and control groups and withhold intervention to one group. Therefore, instead of foregoing the study altogether, an alternative research design was used which is called a quasi-experimental research design. This research design is distinguished from experimental research design due to lack of random assignments of subjects to experimental and comparison group (Lal Das, 2010). Through a random sampling method, 40 respondents aged 60 years and above were chosen as the sample size of the study. A structured interview schedule was used for collecting baseline and post-intervention data.

\section{The Village}

Madwana is situated $50 \mathrm{~km}$ away from the capital city, Lucknow, Uttar Pradesh in northern part of India. As per the Census of India (2011), the total population of Madwana is 4393. It is a community consisting of significantly 2159 Scheduled Castes ${ }^{1}$ (SC) population. Approximately, 2701 people are literate in this village, which consists of 1555

\footnotetext{
${ }^{1}$ The Scheduled Castes is historically disadvantaged people recognised in the Constitution of India. During the period of British rule in the Indian subcontinent, they were known as the Depressed Classes. In modern literature, the Scheduled Castes are sometimes referred to as Dalits. The Scheduled Castes comprise about $16.6 \%$ of India's population (according to the 2011 census). The Constitution (Scheduled Castes) Order, 1950 lists 1,108 castes across 29 states in its First Schedule.
} 
males and 1146 females. In addition, one fourth of the total population work for their livelihood while others are dependent. The main sources of livelihood are cultivation followed by agricultural labourers, and small housing industries. Bakshi Ka Talab (BKT) is the nearest town for the people of this village. This area is famous for mangoes and chikan (a traditional embroidery style of Lucknow). Almost all the houses in the village are made of mud (that is, kachcha or non-permanent) and thatched while few are pucca (permanent). Motorcycle and bicycle remain the basic means of transportation. The nearest public transport is $8 \mathrm{~km}$ away and located at BKT. This compels one to imagine that without public transport, how inconvenient, challenging and expensive is to reach this village. Like other parts of India in general and UP in particular, Madwana too bear a patriarchal structure. Working women, who belong to the SC community and earn daily wages as farm labourers appear to be better off in respect of income in comparison to women from traditionally land holding families. Besides, these women also engage themselves chikan embroidery to support their family. Madwana is no different from other parts of India, when it comes to seeking educational opportunities between boys and girls - the boys are given more importance than the girls are. However, there is only an upper primary school available at the village, which caters to the educational needs of the children.

\section{The Situational Analysis}

In order to understand the existing condition of the respondents, the researcher established rapport with the respondents through regular home visits and gathered information on their existing socio-economic and mental health condition by administering the interview schedule. The baseline situation of the elderly is described below:

\section{Socio-economic Background of the Respondents}

Age

Chronological age is a significant indicator of allocation of roles and responsibilities in any society. Age is an important variable on the basis of which all societies make assumptions about the appropriate behaviours and levels of functioning of people. Hence, grey hair would bring a unique authority and power to a person in the family and the community (Panda, 2005). In the present study, the age of the respondents ranges between 60 to 94 years. Based on their age, the respondents were classified to facilitate further analysis into various sub-groups: that is, 60-69 years, 70-79 years, 80-89 years, and 90 years and above. The survey data also revealed that the majority of the respondents belong to 60-69 years, while 10 per cent of the respondents belong to 90 years and above.
Sex

The present study covered equal percentages of male and female respondents amounting to 50 per cent each. Approximately, 17.50 per cent male respondents belong to the age group 70-79 years while about 25 per cent females belong to the age group of 60-69 years.

\section{Marital Status}

The relationship between husband and wife is an important source for maintaining both socio-emotional and economic support (Ward, 1979). In the present study, the marital status of the respondents was classified into three categories: married, widow and widower. Half of the respondents were married while 30 per cent were widows. Interesting and surprisingly, a substantial proportion (20\%) of widowers were found in the study.

\section{Caste}

Caste system is a unique characteristic of Hindu society. This age-old institution has stratified the society into four varnas, that is, Brahmin, Kshatriya, Vaishya and Shudra. After independence, the Government of India tried to improve the situation of underprivileged sections, officially termed as Scheduled Castes (SC), Scheduled Tribes (ST) and Other Backward Classes (OBC) through several affirmative actions (Panda, 2005). In the study, respondents were found from three diverse caste categories such as General, OBC, and SC. The study found that the respondents from General $(35 \%)$ and SC $(35 \%)$ category were higher in proportionate to $\mathrm{OBC}(30 \%)$ category in each village.

\section{Educational Status}

In the present study, the respondents have various levels of education: elementary, high school and intermediate. A significant proportion of the respondents is illiterate, while the majority of the respondents $(47.50 \%)$ has attained an education up to elementary level.

\section{Occupation}

The study reveals that the respondents are engaged mainly in two types of occupation: agriculture and daily wage labour, while 45 per cent are without work. Rest of them are engaged either as agriculture or daily wage labourers, with majority being involved in agriculture related works.

\section{Monthly Income}

The research unveils three categories of income prevalent in the Madwana village. They are no income, income less than Rs. 1500, and income between Rs. 1500 to 3000 . Majority of the respondents are without any income and live as dependents of their families. 45 per cent of the respondents are unemployed (Table 1). It is also apparent from Table 1 that the monthly income of 35 per cent of the respondents is in between Rs. 1500 to 3000 . 
Table 1. Socio-economic profile of the respondents by age

\begin{tabular}{|c|c|c|c|c|c|}
\hline \multirow[b]{2}{*}{ Variables } & \multicolumn{4}{|c|}{ Age Group $(\mathrm{N}=40)$} & \multirow[b]{2}{*}{ Total } \\
\hline & $60-69$ & $70-79$ & $80-89$ & $>/=90$ & \\
\hline Age & $\begin{array}{c}16 \\
(40.00)\end{array}$ & $\begin{array}{c}10 \\
(25.00)\end{array}$ & $\begin{array}{c}10 \\
(25.00)\end{array}$ & $\begin{array}{c}4 \\
(10.00)\end{array}$ & $\begin{array}{c}40 \\
(100.00)\end{array}$ \\
\hline \multicolumn{6}{|l|}{ Sex } \\
\hline Male & $\begin{array}{c}6 \\
(15.00)\end{array}$ & $\begin{array}{c}7 \\
(17.50)\end{array}$ & $\begin{array}{c}6 \\
(15.00)\end{array}$ & $\begin{array}{c}1 \\
(2.50)\end{array}$ & $\begin{array}{c}20 \\
(50.00)\end{array}$ \\
\hline Female & $\begin{array}{c}10 \\
(25.00)\end{array}$ & $\begin{array}{c}3 \\
(7.50)\end{array}$ & $\begin{array}{c}4 \\
(10.00)\end{array}$ & $\begin{array}{c}3 \\
(7.50)\end{array}$ & $\begin{array}{c}20 \\
(50.00)\end{array}$ \\
\hline \multicolumn{6}{|l|}{ Marital status } \\
\hline Married & $\begin{array}{c}13 \\
(32.50)\end{array}$ & $\begin{array}{c}4 \\
(10.00)\end{array}$ & $\begin{array}{c}2 \\
(5.00)\end{array}$ & $\begin{array}{c}1 \\
(2.50)\end{array}$ & $\begin{array}{c}20 \\
(50.00)\end{array}$ \\
\hline Widow & $\begin{array}{c}2 \\
(5.00)\end{array}$ & $\begin{array}{c}5 \\
(12.50)\end{array}$ & $\begin{array}{c}4 \\
(10.00)\end{array}$ & $\begin{array}{c}1 \\
(2.50)\end{array}$ & $\begin{array}{c}12 \\
(30.00)\end{array}$ \\
\hline Widower & $\begin{array}{c}1 \\
(2.50)\end{array}$ & $\begin{array}{c}1 \\
(2.50)\end{array}$ & $\begin{array}{c}4 \\
(10.00)\end{array}$ & $\begin{array}{c}2 \\
(5.00)\end{array}$ & $\begin{array}{c}8 \\
(20.00)\end{array}$ \\
\hline \multicolumn{6}{|l|}{ Caste } \\
\hline General & $\begin{array}{c}5 \\
(12.50)\end{array}$ & $\begin{array}{c}4 \\
(10.00)\end{array}$ & $\begin{array}{c}3 \\
(7.50)\end{array}$ & $\begin{array}{c}2 \\
(5.00)\end{array}$ & $\begin{array}{c}14 \\
(35.00)\end{array}$ \\
\hline Other Backward Class & $\begin{array}{c}5 \\
(12.50)\end{array}$ & $\begin{array}{c}2 \\
(5.00)\end{array}$ & $\begin{array}{c}4 \\
(10.00)\end{array}$ & $\begin{array}{c}1 \\
2.50)\end{array}$ & $\begin{array}{c}12 \\
(30.00)\end{array}$ \\
\hline Scheduled Caste & $\begin{array}{c}6 \\
(15.00)\end{array}$ & $\begin{array}{c}4 \\
(10.00)\end{array}$ & $\begin{array}{c}3 \\
(7.50)\end{array}$ & $\begin{array}{c}1 \\
(2.50)\end{array}$ & $\begin{array}{c}14 \\
(35.00)\end{array}$ \\
\hline \multicolumn{6}{|l|}{ Educational status } \\
\hline Illiterate & $\begin{array}{c}1 \\
(2.50)\end{array}$ & $\begin{array}{c}4 \\
(10.00)\end{array}$ & $\begin{array}{c}6 \\
(15.00)\end{array}$ & $\begin{array}{c}3 \\
(7.50)\end{array}$ & $\begin{array}{c}14 \\
(35.00)\end{array}$ \\
\hline Elementary & $\begin{array}{c}12 \\
(30.00)\end{array}$ & $\begin{array}{c}4 \\
(10.00)\end{array}$ & $\begin{array}{c}2 \\
(5.00)\end{array}$ & $\begin{array}{c}1 \\
(2.50)\end{array}$ & $\begin{array}{c}19 \\
(47.50)\end{array}$ \\
\hline High school & $\begin{array}{c}3 \\
(7.50)\end{array}$ & $\begin{array}{c}2 \\
(5.00)\end{array}$ & $\begin{array}{c}2 \\
(5.00)\end{array}$ & $\begin{array}{c}0 \\
(0.00)\end{array}$ & $\begin{array}{c}7 \\
(17.50)\end{array}$ \\
\hline \multicolumn{6}{|l|}{ Occupation } \\
\hline No work/unemployed & $\begin{array}{c}2 \\
(5.00)\end{array}$ & $\begin{array}{c}3 \\
(7.50)\end{array}$ & $\begin{array}{c}9 \\
(22.50)\end{array}$ & $\begin{array}{c}4 \\
(10.00)\end{array}$ & $\begin{array}{c}18 \\
(45.00)\end{array}$ \\
\hline Agriculture & $\begin{array}{c}7 \\
(17.50)\end{array}$ & $\begin{array}{c}6 \\
(15.00)\end{array}$ & $\begin{array}{c}1 \\
(2.50)\end{array}$ & $\begin{array}{c}0 \\
(0.00)\end{array}$ & $\begin{array}{c}14 \\
(35.00)\end{array}$ \\
\hline Daily wage labour & $\begin{array}{c}7 \\
(17.50)\end{array}$ & $\begin{array}{c}1 \\
(2.50)\end{array}$ & $\begin{array}{c}0 \\
(0.00)\end{array}$ & $\begin{array}{c}0 \\
(0.00)\end{array}$ & $\begin{array}{c}8 \\
(20.00)\end{array}$ \\
\hline \multicolumn{6}{|l|}{ Monthly income } \\
\hline No income & $\begin{array}{c}2 \\
(5.00)\end{array}$ & $\begin{array}{c}3 \\
(7.50)\end{array}$ & $\begin{array}{c}9 \\
(22.50)\end{array}$ & $\begin{array}{c}4 \\
(10.00)\end{array}$ & $\begin{array}{c}18 \\
(45.00)\end{array}$ \\
\hline > Rs. 1500 & $\begin{array}{c}7 \\
(17.50)\end{array}$ & $\begin{array}{c}1 \\
(2.50)\end{array}$ & $\begin{array}{c}0 \\
(0.00)\end{array}$ & $\begin{array}{c}0 \\
(0.00)\end{array}$ & $\begin{array}{c}8 \\
(20.00)\end{array}$ \\
\hline Rs. 1500 to Rs. 3000 & $\begin{array}{c}7 \\
(17.50)\end{array}$ & $\begin{array}{c}6 \\
(15.00)\end{array}$ & $\begin{array}{c}1 \\
(2.50)\end{array}$ & $\begin{array}{c}0 \\
(0.00)\end{array}$ & $\begin{array}{c}14 \\
(35.00)\end{array}$ \\
\hline
\end{tabular}

Note. The figures in the parenthesis represent the percentage

\section{Mental Health Condition}

In the context of social work practice, there are varying definitions of mental health. These concepts are socially constructed and therefore, differ between cultures, communities and periods of time (Connor-Greene, 2009). The World Health Organization (WHO) conceptualizes mental health within a holistic definition of health that is "a state of physical, mental and social well-being not merely the absence of disease or infirmity". The mental health condition of the elderly during baseline phase has been described below:

\section{Ability to express emotion}

Emotions are the conscious feeling of the elderly, which is associated with their mood, temperament, personality, and mental states. Respondents were asked to state whether they are able to express their emotions with their family members. 55 per cent of those who were surveyed indicated that they were hardly able to express their emotions with their family members. While 25 per cent of the respondents were able to express some form $t$ of their emotions, only 20 per cent were comfortable in expressing their emotions fully.

\section{Depression}

Just over half $(57.50 \%)$ of the respondents felt depressed frequently. Approximately, 30 per cent of the respondents feel depressed to some extent while 13 per cent rarely feel depressed. This minority of elderly, who seldom felt depressed live with their spouse and other family members and bear no liabilities. These respondents receive good familial support. The research unfolds that the familial problems are the key sources of depression among the respondents. The loss of their dear ones, poor economic and health condition, lack of support within the family, and family liabilities are major factors, which affect the health condition of rural elderly. 


\section{Sleeplessness}

Research reveals that about 40 per cent of the respondents frequently experience sleeplessness while about 27.50 per cent hardly experience the problem of sleeplessness. Causes of sleeplessness are also similar to that of depression: social and financial liabilities, loss of dear ones affect the sleeping patterns of the respondents.

\section{Loneliness}

Loneliness is a complex and usually unpleasant emotional response to isolation. Loneliness typically includes anxious feelings about lack of connectedness or communality with other beings, both in the present and extending into the future. As such, loneliness can be felt even when surrounded by other people. The causes of loneliness are varied such as social, mental, emotional, and spiritual factors. Loneliness is "[c]aused not by being alone but by being without some definite needed relationships" (Weiss, 1973: 17). In the present study, it was found that about 30 per cent of the respondent's experiences loneliness to large extent though around 28 per cent seldom experience the complexity of loneliness in their lives.

\section{Memory Loss}

It is apparent from the research that as the elderly are getting old, their ability to remember and recognize seems to have reduced. About 55 per cent per cent of the respondents experience memory loss whereas 45 per cent suffer no problem from the loss of memory.

\section{Social Work Intervention}

After comprehending the detailed information about the existing mental health condition of the elderly, the researcher formulated a set of intervention strategies to address the existing problems of the respondents in their social environment. The social work intervention strategies include sensitizing respondents and family members on various health aspects, creating better awareness about their health, enhancing coping mechanism. These intervention strategies were carried out through counselling, conducting motivational programmes, and developing the strengths of the older adults by identifying their skills, capacities, and strengths to combat with their existing health condition. Pulla (2012) states that people possess strengths and resources for their own empowerment. The process of intervention involved regular home visits, leading to better rapport and trust, which in turn helped the researcher implement a successful intervention. The brief descriptions about the techniques used are as follows:

\section{Awareness, Motivational, Recreational, and Sensitization Programmes}

As the name suggests, these programmes were implemented with all the participants of the research along with their family members, and society by using various techniques such as really, counselling, group discussions, and recreational activities. These programmes provided opportunities for information gathering in order to improve understanding and develop competencies and skills necessary to enable changes in their situation.

\section{Cognitive Therapy}

Among the various therapy approaches, cognitive therapy had demonstrated significant effectiveness in the reduction of depression (Beck, Resnik, and Lettieri, 1974). The basic assumption underlying cognitive therapy is that dysfunctional cognition makes a person vulnerable to depression and lower self-esteem (Hammen, 1995). In the process, it was explained to the respondents that there were alternatives to their current problem producing behaviours. While addressing such dichotomous thinking and ineffective problem solving, the development of hope was facilitated. Importantly, a sense of optimism was instilled among the respondents. The respondents were explicitly told that 'feelings are not facts' and feeling 'hopeless' does not mean that the situation is hopeless. The roles, the attitudes and beliefs played in creating their problematic emotions and behaviours, the degree to which they believed that they caused or controlled the events in their life were explained. It was helpful to demonstrate to the respondents that emotional state could be improved by changing how one processed experience. One of the many ways of demonstrating this point was to ask the respondents to think of examples of people coping well in difficult circumstances and to speculate how they managed to maintain their emotional well-being.

\section{Counselling}

Counselling was used at various stages while dealing with individual cases, interacting with children or family members of elderly, and society. It is a personal help directed toward the solution of a problem, which a person finds that one cannot solve one's problem, seeks the help of a skilled person whose knowledge, experience and general orientation can assist finding a possible solution.. Information and clarification are used for making the client aware of the problem in a psychological help. Respondents were provided psychological support by counselling to decrease tension, sleeplessness, and loneliness.

\section{Values Followed}

Primary core values of social work, which were evident during the intervention, include dignity and worth of the person, importance of human relationship, competency, integrity, service, commitment and responsibility. The researcher upheld the all the values while dealing with the respondents. 
Table 2. Impact of SWI on mental health of the respondents

\begin{tabular}{|c|c|c|c|}
\hline Variables & Pre-assessment & Post-assessment & Impact \\
\hline Ability to express the emotions & 55.00 & 45.00 & -10.00 \\
\hline Depression & 57.50 & 35.00 & -22.50 \\
\hline Sleeplessness & 40.00 & 22.50 & -17.50 \\
\hline Loneliness & 30.00 & 17.50 & -12.50 \\
\hline Memory Loss & 55.00 & 52.50 & -2.50 \\
\hline
\end{tabular}

Note. The figures in the table represent the percentage.

\section{Application of Social Work Principles}

The researcher had carefully applied various principles of social work such as the principle of acceptance, client's right to self-determination, communication, individualization and confidentiality, etc. The application of the principle of acceptance was evident in the researcher's approach as he had accepted the situation and difficulties of the respondents and understood the client's strengths, limitations, potentialities, weaknesses, and misunderstanding. The principle of controlled emotional involvement that was applied by the researcher was really needed in interventions particularly with individuals.

\section{Impact of Social Work Intervention}

After implementing social work intervention, post-intervention assessment was conducted. To evaluate the whole process and to find out the impact of social work intervention, similar interview schedule was administered which was used in baseline survey. The researcher had an interview session with all the respondents. The post-intervention assessment showed that social work intervention made significant impact in improving the quality of life of the elderly participants of the study by reducing their mental stress (please refer to Table 2). Data reveals that before intervention about 55 per cent of the respondents were hardly able to express their emotions with their family members. However, the post-intervention assessment reveals $\mathrm{s}$ that the percentage of such respondents has been reduced up to 10 per cent. Similarly, in the pre-intervention assessment, approximately 58 per cent respondents were experiencing high rate of depression, but the post-intervention assessment reveals that this figure came down to 35 per cent. This implies though the intervention was successful but still a significant percentage of the population considered in the research continue to remain depressed Again in the pre-intervention survey, approximately 40 per cent respondents were experienced sleeplessness to a large extent but post-intervention assessment unveils that currently about 23 per cent respondents experience sleeplessness. In terms of the variable 'loneliness', in our pre-intervention assessment approximately, 30 per cent respondents experienced loneliness to a large extent whereas post-intervention assessment reveals that the figure almost reduced to half, that is approximately, 18 per cent feels lonely even when surrounded by friends and families. When the last variable 'memory loss' was considered, the pre-intervention assessment showed that about 55 per cent respondents experienced some form of memory loss whereas post-intervention assessment reveals a slight decrease of the figure, which stands at 53 per cent. Memory loss is of course a highly complex medical symptom. Hence, further research and serious medical intervention is necessary to assess the loss.

\section{Conclusion}

The study assessed the impact of social work intervention in improving the mental health condition of elderly. Mental health is an important aspect in human life especially at the later stage of life. The WHO defines mental health as "a state of well-being in which the individual realizes his or her own abilities, can cope with the normal stresses of life, can work productively and fruitfully and is able to make a contribution to his or her community. The present social intervention was found to be effective in promoting their abilities to cope up with their mental health problems such as depression, sleeplessness, and loneliness. The respondents were motivated for living happily and sharing their feelings to reduce stress. The researcher has successfully accomplished the objectives of the study. Therefore, the social work intervention played a significant role in improving the quality of life and well-being in terms of good mental health of the rural elderly in India.

\section{REFERENCES}

Beck, A. Resnik, H., and Lettieri, D. (1974). The Prediction of Suicide. In Encyclopedia of Social Work, (Volume 2, Edition 18). Silver Spring: National Association of Social Researchers.

Connor-Greene, P. (2009). Interdisciplinary critical inquiry: Teaching about the social construction of madness. Teaching of Psychology, 33(1), 6-13.

Hammen, C. (1995). The Social Context of Risk for Depression. In K. Craig and K. S. Dobson (Eds.), Anxiety and Depression in Adults and Children. Thousand Oaks: Sage Publications. 
Lal Das, D. K. (2010). Introduction to Methods of Research in Social Work. In Gracious Thomas (Eds.), Social Work Research MSW 006. New Delhi: IGNOU.

Panda, A. K. (2005). Elderly Women in Megapolish. New Delhi: Concept Publishing Company.

Pulla, V. (2012). What is strength based practice all about? In Pulla, V., Chenoweth, L., Francis, A., and Bakaj, S. (Eds.). Papers in Strength based Practice. New Delhi: Allied Publications.
Rajan, S. I. and Kumar, S. (2003). Living Arrangements among Indian Elderly: New Evidence from National Family Health Survey. Economic and Political Weekly, Vol. 38, No. 1 (Jan. 4-10, 2003), pp. $75-80$.

Ward, R. A. (1979). The Aging Experience - An Introduction to Social Gerontology. New York: J. B. Lippincott Company.

Weiss, R. (1973). Loneliness: the experience of emotional and social isolation. Cambridge, Mass: MIT Press. 